\title{
O AGENTE COMUNITÁRIO DE SAÚdE E A VIOLÊNCIA CONTRA A MULHER
}

\author{
Originais recebidos em: 16/05/2011 \\ Aceito para publicação em: 13/02/2012
}

Leide Sayuri Ogasawara

Universidade Federal de Santa Catarina leidesayuri@gmail.com

Patrícia Alves de Souza

Universidade Federal de Santa Catarina p.as@ig.com.br

Jane Maria de Souza Philippi

Universidade Federal de Santa Catarina janemsp@gmail.com

\section{Resumo}

A violência é o uso intencional de força física ou do poder, real ou em ameaça, contra si próprio, contra outra pessoa ou contra um grupo ou uma comunidade e que resulte ou tenha possibilidade de resultar em lesão, morte, dano psicológico, deficiência de desenvolvimento ou privação. A violência, nos seus vários tipos (doméstica, sexual, física e psicológica), já é considerada uma endemia que afeta a saúde individual e coletiva. A Casa da Mulher Catarina, projeto de extensão do Departamento de Saúde Pública da Universidade Federal de Santa Catarina, atuou em 2010 na disseminação do conhecimento sobre a violência contra a mulher. Realizou capacitação para 174 agentes comunitários de saúde (ACSs) das Unidades de Saúde de São José/SC, com o objetivo de sensibilizá-los sobre a violência. Ao final, avaliaram-se as atividades com perguntas sobre a violência, as quais foram aprovadas pelo Comitê de Ética da UFSC/CEPSH, sob o número 790/2010. A maioria, $72 \%$, respondeu que às vezes a mulher é tratada com respeito no Brasil; $22 \%$ responderam que a mulher não é respeitada, $4 \%$ responderam que a mulher é tratada com respeito; e $2 \%$ não responderam. O ambiente apontado como sendo o de maior desrespeito foi a sociedade (38\%), seguido do familiar (35\%), do local de trabalho $(25 \%)$, e (2\%) não responderam e/ou responderam ser em outros locais. Os ACSs mostraram desconhecimento do assunto e interesse por ele. Acredita-se que a capacitação atingiu as expectativas, e que agora os agentes saibam identificar a violência contra a mulher na sua comunidade e sejam multiplicadores das ações contra a violência.

Palavras-chave: Violência contra a mulher. Agentes Comunitários de Saúde. Direitos da mulher. Sistema Único de Saúde.

\section{THE HEALTH COMMUNITY AGENT AND VIOLENCE AGAINST WOMEN}

\begin{abstract}
Violence is the intentional use of physical strength or power, either real or as a threat against oneself, another person, a group or a community, which results or may result in injuries, death, psychological damage or insufficient development or even privacy. There are several kinds of violence: domestic, sexual, physical and psychological, which has been considered as an endemic problem that affects both individual and collective health. Therefore, Casa da Mulher Catarina, an extension project of Federal University of Santa Catarina has worked within the dissemination of knowledge about violence against women. In 2010, it was carried out a capacitating course for 174 Health Community Agents of Health Units of São Jose municipality, aiming to sensitize these professionals about violence. The project, which was approved by the Ethical Board of UFSC (CEPSH 790/2010). It was applied a questionnaire for the agents preserving their anonymity. Results demonstrated that out of 174 participants, $72 \%$ think women are sometimes treated with respect, $22 \%$ think women are not respected at all, $4 \%$ believe women are respectfully treated in Brazil while $2 \%$ questionnaires were not answered. According to these Agents, society is the environment in which women are less respected $(38 \%)$, followed by their families $(35 \%)$ and working place $(25 \%)$. The HCA showed interest, but also lack of knowledge about the subject. Thus, it is believed the course reached its aims by enabling the agents to identify violence against women in their local communities and also to multiply actions to have it extinguished.
\end{abstract}

Key-words: Violence against women. Health Community Agents. Women rights. Health Unified System. 


\section{INTRODUÇÃO}

A violência doméstica contra a mulher saiu do manto da invisibilidade, cresceu muito nos últimos anos, tanto nos pequenos como nos grandes centros, e está presente em todas as camadas sociais (SOUZA; DA ROS, 2006). Segundo o Conselho Nacional de Secretários de Saúde (CONASS, 2007), a violência é o resultado do desequilíbrio das relações sociais, políticas e econômicas de um povo. Para Schraiber et al. (2002), ela contribui para o aumento da mortalidade e perda de qualidade de vida, aumento dos custos sociais em saúde e previdência, absenteísmo no trabalho e na escola, e também é uma das causas mais significativas de desestruturação familiar.

A Organização Mundial da Saúde (OMS, 2002) considera violência o uso intencional de força física ou do poder, real ou em ameaça, contra si próprio, contra outra pessoa, ou contra um grupo ou uma comunidade, e que resulte ou tenha possibilidade de resultar em lesão, morte, dano psicológico, deficiência ou privação de desenvolvimento. A violência contra a mulher se traduz em diversas formas — física, psicológica, sexual, moral, etc. — e é considerada doméstica quando é cometida por uma pessoa com que essa mulher tenha vínculo (CFSS, 2002).

Em Santa Catarina, a partir de 2008, ano da implantação do sistema de notificação sobre violência doméstica, sexual e/outras violências, foram registrados, até março de 2010, 1.044 casos notificados, perfazendo 17,4 por 100.000 habitantes (SES/SC, 2008).

A violência doméstica demanda intervenção de diferentes profissionais e instituições distintas (SOUZA; DA ROS, 2006), por isso é importante que os agentes comunitários de saúde desenvolvam habilidades e conheçam algumas técnicas para detectar os sinais de violência, muitas vezes ocultos, descobri-los dentro dos véus da "privacidade" do lar e encaminhá-los corretamente para a assistência.

Em 2006, foi sancionada a Lei 11.340/20, Lei Maria da Penha, promovendo mudanças no Código Penal Brasileiro, como o aumento no rigor das punições de agressores de mulheres, quando a violência ocorre no âmbito doméstico ou familiar, e a possibilidade de os agressores serem presos em flagrante ou terem sua prisão preventiva decretada e de não poderem mais ser punidos com penas alternativas, aumentando o tempo máximo de detenção previsto de um para três anos. A lei, uma punição dos órgãos internacionais de direitos humanos imposta ao Brasil por ter deixado impune o agressor de Maria da Penha, ainda prevê 
medidas que vão desde a saída do agressor do domicílio à proibição de sua aproximação da mulher agredida e dos filhos (BRASIL, 2006).

Existe um certo desconhecimento sobre a violência doméstica, ainda mais por se tratar de um fato privado e que depende de uma intervenção pública. Os problemas gerados comprometem a saúde física e psicológica da mulher, além de refletir negativamente na vida dos filhos (SOUZA, 2002).

Esse panorama reflete a necessidade de se combater, dentro das propostas do Sistema Único de Saúde (SUS), valores e atitudes que tornam as desigualdades como algo natural e que justificam a opressão e a violência contra a mulher (FONSECA et al., 2009).

Dentro desse contexto de saúde, está o agente comunitário de saúde (ACS), que, integrante da Equipe de Saúde da Família (ESF) nas Unidades Locais de Saúde, trabalha diretamente com as famílias, percorrendo as residências dentro de sua área de abrangência. É seu papel: visitas, cadastramento das famílias, orientações sobre problemas de saúde, saneamento e cuidados com higiene pessoal. Ele é, portanto, o profissional que pode identificar situações de violência doméstica e encaminhar os casos para atendimento.

Os agentes habitam o mesmo território em que trabalham e têm condições de avaliar a dinâmica da família, identificando, muitas vezes, as situações de risco (FONSECA et al., 2009). Assim, faz-se necessária a capacitação desse agente e sua sensibilização para o problema da violência contra a mulher, podendo intervir na comunidade e fazer o encaminhamento correto dos casos identificados.

A Casa da Mulher Catarina, projeto de extensão do Departamento de Saúde Pública da Universidade Federal de Santa Catarina, atuou em 2010 na disseminação do conhecimento sobre a violência contra a mulher. Realizou capacitação de agentes comunitários de saúde (ACSs) das Unidades de Saúde de São José/SC, com o objetivo de sensibilizá-los sobre a violência.

\section{MATERIAL E MÉTODOS}

Durante o ano de 2010, a Casa da Mulher Catarina, projeto de extensão do Departamento de Saúde Pública, capacitou agentes comunitários de saúde (ACSs) do Município de São José, em Santa Catarina, com a finalidade de sensibilizá-los sobre a 
violência contra a mulher, melhorando seu conhecimento sobre a violência, a lei Maria da penha e os locais para encaminhamento e atendimento às mulheres vítimas de violência.

Após a capacitação, avaliou-se o conhecimento dos ACSs sobre violência, com a aplicação de questionário, aprovado pelo Comitê de Ética da UFSC, sob número 790/2010, no qual os participantes assinaram um termo de consentimento livre e esclarecido, sendo preservado o anonimato.

\section{RESULTADOS E ANÁLISE}

Foram capacitados 174 ACSs de todas as unidades de saúde do município de São José, Santa Catarina. Durante a capacitação, foram realizadas palestras sobre vários assuntos ligados à violência contra a mulher, como: o que é violência, tipos de violência, o ciclo da violência, Lei Maria da Penha, como e onde denunciar a violência, como e para onde encaminhar a vítima. Após as palestras, houve discussão final e aplicação de questionário sobre violência.

Os palestrantes eram todos profissionais da área da violência contra a mulher da Casa da Mulher Catarina, professores e voluntários, e de órgãos ligados à violência, tanto da área da saúde como da área do serviço social e da justiça, que acolhem as mulheres.

O questionário, aplicado após a capacitação, consistia de duas perguntas sobre a violência. A primeira pergunta era: “A mulher é tratada com respeito no Brasil?”. Nesta pergunta, eram apresentadas três alternativas de resposta: sim, às vezes e não. A segunda pergunta: “Qual é o ambiente em que a mulher é mais desrespeitada?”, apresentava cinco alternativas de resposta: na família, na sociedade, no trabalho, outros locais e não sabe/não quer responder.

Com relação à primeira pergunta, a maioria, 72\%, respondeu que às vezes a mulher é tratada com respeito; $22 \%$ responderam que a mulher não é tratada com respeito; $4 \%$ consideram que a mulher é tratada com respeito; e $2 \%$ não responderam.

Com relação à segunda pergunta, sobre o ambiente em que a mulher é mais desrespeitada, a maioria, 38\%, respondeu ser a sociedade; 35\% acham que é o ambiente familiar; $25 \%$ assinalaram o ambiente de trabalho; $2 \%$ responderam outros locais e/ou não assinalaram. 
O local de maior violência contra a mulher ainda é o ambiente familiar, apesar de a mulher também sofrer violência no ambiente de trabalho, como preconceito e remuneração inferior aos homens.

Dados de Brasil (2009) mostram que no país trabalham mais de 200 mil agentes comunitários de saúde, e o Ministério da Saúde reconhece que o processo de qualificação deve ser permanente, apesar de ter lançado um guia prático para a atuação do agente, com capítulo específico sobre violência familiar.

Fonseca et al. (2009), em questionário aplicado a 17 agentes comunitários de saúde do Distrito de Butantã, na cidade de São Paulo, sobre violência contra a mulher e práticas cuidativas em nível da atenção básica de saúde, encontrou posições apoiadas no senso comum, não diferindo das ideias em geral dos leigos e das mulheres vítimas de violência, e concluiu a necessidade de ser ampliado o espaço de discussão do problema, para o atendimento às mulheres vítimas de violência.

Os ACSs de São José mostraram desconhecimento do assunto e interesse por ele. Acredita-se que a capacitação atingiu seus objetivos, e que os agentes estão sensibilizados ao tema, identificando a violência contra a mulher na sua comunidade e fazendo o papel de multiplicadores das ações contra a violência.

\section{CONSIDERAÇÕES FINAIS}

A capacitação realizada atingiu seus objetivos ao informar e conscientizar os agentes comunitários de saúde sobre a violência contra a mulher e expor-lhes as ferramentas necessárias para o atendimento à violência. Como se trata de um grande problema de saúde pública no Brasil, é importante a contribuição desse profissional, tanto como multiplicador dos conhecimentos sobre a violência doméstica quanto para o correto encaminhamento à assistência.

Os ACSs têm informações diretamente das famílias e fazem a ponte entre o público e o domiciliar; portanto, podem auxiliar na divulgação dos locais onde as mulheres devem procurar ajuda.

A avaliação permitiu inferir que são necessárias futuras capacitações, bem como fases mais avançadas de debates e discussão, e até de casos reais, que muitas vezes são divulgados na mídia e geram mortes previsíveis. 
O estudo possui os limites referentes à opinião particular de todos os ACSs sobre o que consideram um assunto importante. Assim, entre os temas que perfazem a violência, algumas polêmicas foram levantadas. Mesmo assim, ficou evidente a necessidade da continuidade da capacitação não só dos agentes, mas de todos os profissionais envolvidos no atendimento à comunidade. $\mathrm{O}$ despreparo frente à violência contra a mulher indica a necessidade de investir nos profissionais de saúde para que eles se sintam capazes de criar estratégias de identificação e intervenção.

\section{REFERÊNCIAS}

BRASIL. Lei $n^{\circ} 11.340$, de 7 de agosto de 2006. Cria mecanismos para coibir a violência doméstica e familiar contra a mulher, nos termos do $\S 8^{\circ}$ do art. 226 da Constituição Federal, da Convenção sobre a Eliminação de Todas as Formas de Discriminação contra as Mulheres e da Convenção Interamericana para Prevenir, Punir e Erradicar a Violência contra a Mulher; dispõe sobre a criação dos Juizados de Violência Doméstica e Familiar contra a Mulher; altera o Código de Processo Penal, o Código Penal e a Lei de Execução Penal; e dá outras providências. Brasília, D.O.U. de 08 de agosto de 2006.

Ministério da Saúde. Secretaria de Atenção à Saúde. Guia Prático do Agente Comunitário de Saúde. Brasília: Ministério da Saúde, 2009. 260 p.

COLETIVO FEMINISTA SEXUALIDADE E SAÚDE - CFSS. Universidade de São Paulo. Centro de Saúde - Escola Prof. Samuel Barnsley Pessoa. Mulheres em situação de violência - Guia de Serviços. 3 ed. São Paulo: Coletivo Feminista Sexualidade e Saúde, 2002. Disponível em: <http://www.bvsde.paho.org/bvsacd/cd26/fulltexts/0166.pdf-16/05/2011>. Acessado em 16 maio 2011.

CONSELHO NACIONAL DE SECRETÁRIOS DE SAÚDE (CONASS). Violência uma epidemia silenciosa. Conselho Nacional de Secretários de Saúde. Documento no 15. Brasília: CONASS, 2007.

FONSECA, Rosa Maria Godoy Serpa de; LEAL, Ana Emília Ramos Bagueira; SKUBS, Thaís; GUEDES, Rebeca Nunes; EGRY, Emiko Yoshikawa. Violência doméstica contra a mulher na visão do Agente Comunitário de Saúde. Rev Latino Am. Enferm. [on line] 2009; v. 17, n. 6, p. 974-980. Disponível em: <http://www.scielo.br/pdf/rlae/v17n6/pt_08.pdf>. Acesso em 15 maio 2010.

ORGANIZAÇÃO MUNDIAL DE SAÚDE (OMS). Relatório Mundial sobre Violência e Saúde. Genebra: OMS: 2002.

SCHRAIBER, Lilia Blima; d'OLIVEIRA, Ana Flávia P. L.; FRANÇA-JUNIOR, Ivan; PINHO, Adriana A. Violência contra a mulher: estudo em uma unidade de atenção primária à saúde. Rev. Saúde Pública, 2002; 36(4): 470-7. São Paulo. Disponível em 
$<$ http://www.scielo.br/scielo.php?script=sci_arttext\&pid=S0034-89102002000400013 \& $\operatorname{lng}$ $=$ em\&nrm=iso $>$. Acesso em: 16 maio 2011 .

SECRETARIA DE ESTADO DA SAÚDE DE SANTA CATARINA-SES/SC. Diretoria de Vigilância Epidemiológica. Notificação de violência no SINAN NET. DIVE/SES/SC. Florianópolis, 2008.

SOUZA, Patrícia Alves (Dissertação). Os possíveis motivos do adiamento da denúncia de mulheres vítimas de violência física conjugal: estudo em grupo de mulheres atendidas no Cevic - Florianópolis, 2002. Programa de Pós-Graduação em Saúde Pública/UFSC, Florianópolis.

SOUZA, Patrícia Alves; DA ROS, Marco Aurélio. Os motivos que mantêm as mulheres vítimas de violência no relacionamento violento. Rev. Cien. Humanas. Florianópolis: EDUFSC, 2006; 40, 509-26. 